\title{
A Comparison of Equivalent Doses of Lidocaine and Articaine in Maxillary Posterior Tooth Extractions: Case Series
}

\author{
Christopher C. Friedl' ${ }^{1}$, Jill Bashutski², Navid Rashidi ${ }^{3}$ \\ ${ }^{1}$ Private Practice, Fort Collins, Colorado, USA. \\ ${ }^{2}$ Department of Periodontics and Oral Medicine, School of Dentistry, University of Michigan, Ann Arbor Michigan, USA. \\ ${ }^{3}$ Department of Periodontics and Allied Dental Programs, School of Dentistry, Indiana University, Indianapolis, Indiana, USA.
}

\author{
Corresponding Author: \\ Navid Rashidi \\ 350 North Meridian Street, Unit 407, Indianapolis, IN 46204 \\ United States of America \\ Phone: (316) 992-8973 \\ E-mail:nrashidi@umich.edu
}

\begin{abstract}
Objectives: Local anaesthesia is the standard of care during dental extractions. With the advent of newer local anesthetic agents, it is often difficult for the clinician to decide which agent would be most efficacious in a given clinical scenario. This study assessed the efficacy of equal-milligram doses of lidocaine and articaine in achieving surgical anaesthesia of maxillary posterior teeth diagnosed with irreversible pulpitis.

Material and Methods: This case-series evaluated a total of 41 patients diagnosed with irreversible pulpitis in a maxillary posterior tooth. Patients randomly received an infiltration of either $3.6 \mathrm{~mL}$ (72 mg) 2\% lidocaine with 1:100,000 epinephrine or $1.8 \mathrm{~mL}$ (72 mg) 4\% articaine with 1:100,000 epinephrine in the buccal fold and palatal soft tissue adjacent to the tooth. After 10 minutes, initial anaesthesia of the tooth was assessed by introducing a sterile 27-gauge needle into the gingival tissue adjacent to the tooth, followed by relief of the gingival cuff. Successful treatment was considered to have occurred when the tooth was extracted with no reported pain. Data was analyzed with the Fisher's exact test, unpaired t-test and normality test. Results: Twenty-one patients received lidocaine and 20 received articaine. Forty of the 41 patients achieved initial anaesthesia 10 minutes after injection: 21 after lidocaine and 19 after articaine $(\mathrm{P}=0.488)$. Pain-free extraction was accomplished in 33 patients: 19 after lidocaine and 14 after articaine buccal and palatal infiltrations $(\mathrm{P}=0.226)$.

Conclusions: There was no significant difference in efficacy between equivalent doses of lidocaine and articaine in the anaesthesia of maxillary posterior teeth with irreversible pulpitis.
\end{abstract}

Keywords: lidocaine; articaine; teeth; pulpitis; local anesthesia; anesthesia, infiltration.

\author{
Accepted for publication: 28 June 2012. \\ To cite this article: \\ Friedl CC, Bashutski J, Rashidi N. A Comparison of Equivalent Doses of Lidocaine and Articaine in Maxillary Posterior Tooth \\ Extractions: Case Series. \\ J Oral Maxillofac Res 2012;3(2):e4 \\ URL: http://www.ejomr.org/JOMR/archives/2012/2/e4/v3n2e4ht.pdf \\ doi: $10.5037 /$ jomr.2012.3204
}




\section{INTRODUCTION}

In recent years, a significant amount of research has been conducted to investigate the efficacy of $2 \%$ lidocaine versus $4 \%$ articaine [1-5]. One common topic of investigation is to compare the effectiveness of these two anesthetics in challenging situations, such as the ability to anesthetize maxillary teeth with irreversible pulpitis $[1,6]$. Several studies comparing the efficacy of $2 \%$ lidocaine and $4 \%$ articaine have had contradictory outcomes [1-7]. Some studies and literature reviews have shown a statistically significant advantage to the use of articaine, especially on teeth with irreversible pulpitis $[\underline{6}, \underline{8}]$. One such study found that $4 \%$ articaine was 1.59 to 3.76 times more likely to produce anesthetic success than of $2 \%$ lidocaine, and 3.81 times more likely when given as an infiltration [ $[\mathrm{g}$ ]. Similarly, a separate study found $4 \%$ articaine with 1:100,000 epinephrine to be superior to $2 \%$ lidocaine with 1:100,000 epinephrine in patients with irreversible pulpitis when given as a maxillary buccal infiltration [6]. Still other studies have found there to be no significant difference in the efficacy of $2 \%$ lidocaine $(1: 100,000)$ and $4 \%$ articaine $(1: 100,000)$ in achieving anaesthesia of maxillary teeth with irreversible pulpitis $[\underline{1}, \underline{7}, \underline{10}]$.

One major consideration in reviewing many of these studies is that the comparison of the efficacy of $2 \%$ lidocaine versus $4 \%$ articaine is made using equal volumes of anesthetic instead of equal doses. Considering that a given volume of $4 \%$ articaine contains twice as much active drug as an equivalent volume of $2 \%$ lidocaine, no direct milligram-tomilligram comparison is being performed. As has been discussed by other authors, it would be expected that a $4 \%$ solution would perform better than a $2 \%$ solution given equal volumes of fluid [ $\underline{8}$.

Consequently, the purpose of this case-series study was to investigate the efficacy of $2 \%$ lidocaine $(1: 100,000)$ and $4 \%$ articaine $(1: 100,000)$ in the surgical anaesthesia of teeth with irreversible pulpitis using a milligram-to-milligram comparison of both solutions. The null hypothesis of the present study is that there is no difference in obtaining surgical anaesthesia of maxillary posterior teeth with irreversible pulpitis with the use of $2 \%$ lidocaine $(1: 100,000)$ or $4 \%$ articaine $(1: 100,000)$ when equal-milligram doses are administered. The primary outcome measure was a pain-free extraction procedure of a maxillary posterior tooth diagnosed with irreversible pulpitis.

\section{MATERIAL AND METHODS}

Patient recruitment and data collection for this study took place over the course of 8 months, commencing in August of 2011. Patients were evaluated and treated either in the private dental practice setting in Fort Collins, Colorado, USA, or in the hospital setting in Ann Arbor, Michigan USA.

Forty-one adult patients who presented to one of these two clinical settings on an emergency basis and who were diagnosed with irreversible pulpitis were initially included in this study. Only those patients with a single symptomatic maxillary posterior tooth in the quadrant to receive treatment were included.

Two clinicians confirmed the diagnosis, administered the anesthetic, and performed the extractions. For each individual patient, diagnoses were made and data collected by the same author administering treatment. Diagnosis of irreversible pulpitis was made utilizing the results of cold testing, electronic pulp testing, palpation and percussion sensitivity tests, and radiographic analysis.

All conventional treatment options constituting regional standard of care were verbally presented and discussed with patients for management of their irreversible pulpitis. Various types of treatment were discussed, including root canal therapy, extraction, implant with fixed prosthesis, fixed partial denture or removable prosthesis. Only patients who elected extraction as their treatment of choice were included in this analysis.

Over a period of 8 months, forty-one patients presented for extraction using the criteria defined above and whose data are included in this study. All patients gave verbal consent for data to be collected during their treatment. Patients randomly received one of two types of local anesthetic in equivalent doses. The two compounds administered during this study were $2 \%$ lidocaine HCL with 1:100,000 epinephrine (Lidocaine; Cook-Waite Laboratories, Inc, New York, USA) and 4\% articaine HCL with 1:100,000 epinephrine (Zorcaine; CookWaite Laboratories, New York, USA). Each carpule contained $1.8 \mathrm{~mL}$ solution. The goal was to administer equal doses (mg) of either solution in a fashion that approximates standard clinical administration for a dental extraction.

Each patient received approximately $3 / 4$ of the total anesthetic volume as a buccal infiltration and approximately $1 / 4$ of the total anesthetic volume as palatal infiltration. The two treatment groups were as follows:

Lidocaine infiltration group: each patient received a total of $3.6 \mathrm{~mL}(72 \mathrm{mg}) 2 \%$ lidocaine with $1: 100,000$ epinephrine solution. Approximately $3 / 4$ of the solution volume $(2.7 \mathrm{~mL})$ was administered as a buccal infiltration and approximately $1 / 4(0.9 \mathrm{~mL})$ as a palatal infiltration.

Articaine infiltration group: each patient received 
a total of $1.8 \mathrm{~mL}(72 \mathrm{mg}) 4 \%$ articaine with 1:100,000 epinephrine solution. Approximately $3 / 4$ of the solution volume $(1.35 \mathrm{~mL})$ was administered as a buccal infiltration and approximately $1 / 4(0.45 \mathrm{~mL})$ as a palatal infiltration.

Local anesthetic solution was administered via infiltration at the level of the mucobuccal fold adjacent to the symptomatic tooth, in addition to a palatal infiltration approximately $12-15 \mathrm{~mm}$ apical to the free gingival margin. All solutions were injected using a 27-gauge $20 \mathrm{~mm}$ sterile needle and standard dental aspirating syringe that accepts $1.8 \mathrm{~mL}$ carpules. Each solution, in each site, was deposited over the course of one minute after negative aspiration.

A medical history and vital signs were collected and reviewed with each patient. Any patients with a medical history that contraindicated the use of amide- or estercontaining local anesthetics with epinephrine (e.g., uncontrolled hypertension) were excluded from this study. Patients with an unstable medical history (e.g., recent history of myocardial infarct or poorly controlled diabetes), or other contraindications to oral surgery were also excluded. Patients currently taking any prescription or over-the-counter analgesics were excluded. Patients with allergies or reported adverse events specific to lidocaine, articaine, or their components or who exhibited factors that would compromise data collection (e.g., neuralgia, undergoing pain management) were also excluded from analysis. Prior to administration of local anesthetic, patients were asked to rate the level of discomfort in the affected tooth on a scale of 0 to 10 , with 0 being no pain and 10 being the worst pain ever experienced.

After a period of 10 minutes following the administration of anesthetic solution, initial anaesthesia was assessed by penetrating the buccal and palatal gingival tissues with a sterile 27-gauge needle and asking the patient if any discomfort was experienced. If 0 pain was reported on a scale of 0 to 10 , the gingival cuff around the symptomatic tooth was relieved, and again the patient was asked to report any discomfort. Failures of either test resulted in recording the patient as failure of initial anaesthesia and failure of treatment due to pain. The patient was then managed with further supplementary anesthetic injections as needed.

Upon verification of successful initial anaesthesia, the clinician proceeded to perform extraction of the symptomatic tooth using the usual non-surgical extraction protocol. Before any elevation or forceps application was attempted, a \#7 mucoperiosteal elevator was introduced into the mesial and distal PDL space to verify anaesthesia and aid in atraumatic extraction. If any pain was reported at any point between initial verification of anaesthesia and complete delivery of the symptomatic tooth, the patient was recorded as failure of pain-free treatment and managed with further supplementary anesthetic injections as needed.

\section{Statistical analysis}

Data were analysed with the Fisher's exact test, unpaired Student's t-test and normality test. The statistical significance level was defined at 0.05 . All analysis was recorded and analyzed with InStat statistical analysis software.

\section{RESULTS}

Table 1 summarizes the patient population in the present study. 41 patients were included, 26 females and 15 males. The patient age ranged between 19 and 63 years, with a median of 38 years and a mean of 38.5 years, standard deviation (SD) 12.25 years. The age distribution passed the normality test $(\mathrm{P}>0.10)$. There was no significant difference between females and males in this study with respect to age (Mean \pm $\mathrm{SD}=37.8 \pm 12.9$ for females and $39.7 \pm 11.8$ for males,

Table 1. Patient demographics, initial pain and categories of teeth anesthetized

\begin{tabular}{|c|c|c|c|c|c|c|c|c|}
\hline \multirow{2}{*}{\multicolumn{2}{|c|}{ Patient variable and solution used }} & \multicolumn{2}{|c|}{ Lidocaine } & \multicolumn{2}{|c|}{ Articaine } & \multicolumn{2}{|c|}{ Total } & \multirow{2}{*}{ Pvalue $^{a}$} \\
\hline & & $\mathbf{N}$ & $\%$ & $\mathbf{N}$ & $\%$ & $\mathbf{N}$ & $\%$ & \\
\hline Number & & 21 & 51.2 & 20 & 48.8 & 41 & 100 & \\
\hline \multirow{2}{*}{ Sex } & Male & 6 & 14.6 & 9 & 22 & 15 & 36.6 & \multirow{2}{*}{$0.341^{\mathrm{b}}$} \\
\hline & Female & 15 & 36.6 & 11 & 26.8 & 26 & 63.4 & \\
\hline \multicolumn{2}{|c|}{ Initial pain $(1-10)$} & \multicolumn{2}{|c|}{4.8} & \multicolumn{2}{|c|}{4.2} & & & $0.46^{\mathrm{c}}$ \\
\hline \multicolumn{2}{|c|}{ Premolars } & 9 & 22 & 5 & 12.2 & 14 & 34.1 & \multirow{2}{*}{$0.326^{\mathrm{b}}$} \\
\hline \multicolumn{2}{|l|}{ Molars } & 12 & 29.3 & 15 & 36.6 & 27 & 65.9 & \\
\hline
\end{tabular}

${ }^{a}$ Tested between lidocaine and articaine groups.

bNon significant, Fisher's Exact Test.

'Non significant, unpaired Student's t-test. 
$\mathrm{t}=0.46, \mathrm{P}=0.65)$. There was no significant difference between the proportion of males to females between the lidocaine and articaine groups (Fisher's Exact Test, $\mathrm{P}=0.341)$. There was no significant difference between the lidocaine and articaine groups with respect to the reported pain $(0-10)$ before initiating treatment (averages were 4.8 and 4.2 , respectively).

Of the 41 patients, 21 patients received $3.6 \mathrm{~mL}$ of $2 \%$ lidocaine with 1:100,000 epinephrine, and 20 patients received $1.8 \mathrm{~mL}$ of $4 \%$ articaine with $1: 100,000$ epinephrine. There was no significant difference in gender distribution or initial pain between patients treated by the two examiners.

Table 1 also illustrates that there was no significant difference found between the categories of teeth anesthetized with $2 \%$ lidocaine or $4 \%$ articaine (Fisher's Exact Test, $\mathrm{P}=0.326$ ). Table 2 illustrates that there was no significant difference found in success of initial anaesthesia when tested with sterile 27-gauge needle, or during relief of the gingival cuff between the lidocaine and articaine groups (Fisher's Exact Test $\mathrm{P}=0.488)$. Overall, the success of initial anaesthesia was $97.6 \%$, with the only initial anaesthesia failure occurring during release of the gingival cuff around a molar in the articaine group.

The data in Table 3 show that of those patients who achieved successful initial anaesthesia, there was no significant difference between lidocaine and articaine groups with respect to the categories of teeth anesthetized (Fisher's Exact Test, $\mathrm{P}=0.324$ ). Of the 40 patients for whom initial anaesthesia was successful, 33 $(82.5 \%)$ went on to experience elevation and extraction of the affected tooth without pain, while $7(17.5 \%)$ experienced discomfort during the extraction procedure. Table 4 shows that there was no significant difference in success rates of treatment between the lidocaine and articaine infiltration groups (Fisher's Exact Test, $\mathrm{P}=0.226$ ). There was also no significant difference in success rates of treatment between providers. With respect to the categories of teeth anesthetized, success rates of treatment were similar for both premolars and molars (Fisher's Exact Test, $\mathrm{P}=0.387$ ) for the 40 patients for whom initial anaesthesia was successful (Table 5).

Combining the results of anaesthesia success at all stages of treatment, overall treatment success was noted in 33 of 41 patients $(80.5 \%)$. Table 6 illustrates overall success rates in the lidocaine and articaine groups. Successful treatment was achieved in 19 of 21 patients $(90.5 \%)$ who received $3.6 \mathrm{~mL} 2 \%$ lidocaine $(1: 100,000)$ and in 14 of $20(70 \%)$ patients who received $1.8 \mathrm{~mL}$ $4 \%$ articaine $(1: 100,000)$. There was no significant

Table 2. Successful initial anaesthesia 10 minutes after infiltration

\begin{tabular}{ccccccccc}
\hline \multirow{2}{*}{ Successful initial anaesthesia and solution used } & \multicolumn{2}{c}{ Lidocaine } & \multicolumn{2}{c}{ Articaine } & \multicolumn{2}{c}{ Total } & \multirow{2}{*}{ P value $^{\mathbf{a}}$} \\
\cline { 2 - 8 } & $\mathbf{N}$ & $\mathbf{\%}$ & $\mathbf{N}$ & $\mathbf{\%}$ & $\mathbf{N}$ & $\mathbf{\%}$ & $0.488^{\mathrm{b}}$ \\
Success & 21 & 100 & 19 & 95 & 40 & 97.5 & \\
Failure & 0 & 0 & 1 & 5 & 1 & 2.5 & \\
\hline
\end{tabular}

${ }^{a}$ Tested between lidocaine and articaine groups.

bNon significant, Fisher's Exact Test.

Table 3. The number (\%) of patients with successful initial anaesthesia in different categories of teeth after lidocaine and articaine infiltrations

\begin{tabular}{ccccccccc}
\hline \multirow{2}{*}{ Tooth type anesthetized and solution used } & \multicolumn{2}{c}{ Lidocaine } & \multicolumn{2}{c}{ Articaine } & \multicolumn{2}{c}{ Total } & \multirow{2}{*}{ P value $^{\text {a }}$} \\
\cline { 2 - 8 } & $\mathbf{N}$ & $\mathbf{\%}$ & $\mathbf{N}$ & $\mathbf{\%}$ & $\mathbf{N}$ & $\mathbf{\%}$ & \\
\hline Premolar & 9 & 22.5 & 5 & 12.5 & 14 & 35 & $0.324^{\mathrm{b}}$ \\
Molar & 12 & 30 & 14 & 35 & 27 & 65 & \\
\hline
\end{tabular}

aTested between lidocaine and articaine groups.

${ }^{b}$ Non significant, Fisher's Exact Test.

Table 4. Treatment success after lidocaine and articaine infiltrations in 40 patients with successful initial anaesthesia

\begin{tabular}{ccccccccc}
\hline \multirow{2}{*}{ Treatment outcome and solution used } & \multicolumn{2}{c}{ Lidocaine } & \multicolumn{2}{c}{ Articaine } & \multicolumn{2}{c}{ Total } & \multirow{2}{*}{ P value $^{\text {a }}$} \\
\cline { 2 - 7 } & $\mathbf{N}$ & $\mathbf{\%}$ & $\mathbf{N}$ & $\mathbf{\%}$ & $\mathbf{N}$ & $\mathbf{\%}$ & \\
\hline Successful treatment without pain & 19 & 90.5 & 14 & 73.7 & 33 & 82.5 & $0.226^{\text {b }}$ \\
Failure of treatment due to pain & 2 & 9.5 & 5 & 26.3 & 7 & 17.5 & \\
\hline
\end{tabular}

aTested between lidocaine and articaine groups.

bNon significant, Fisher's Exact Test. 
Table 5. Treatment outcomes by tooth category after lidocaine and articaine infiltrations in 40 patients with successful initial anaesthesia

\begin{tabular}{cccccccc}
\hline \multirow{2}{*}{ Treatment outcome and tooth category } & \multicolumn{2}{c}{ Premolars } & \multicolumn{2}{c}{ Molars } & \multicolumn{2}{c}{ Total } & \multirow{2}{*}{ P value $^{\text {a }}$} \\
\cline { 2 - 7 } & $\mathbf{N}$ & $\mathbf{\%}$ & $\mathbf{N}$ & $\mathbf{\%}$ & $\mathbf{N}$ & $\mathbf{\%}$ & \\
\hline Successful treatment without pain & 13 & 32.5 & 20 & 50 & 33 & 82.5 & $0.387^{\mathrm{b}}$ \\
Failure of treatment due to pain & 1 & 2.5 & 6 & 15 & 7 & 17.5 & \\
\hline
\end{tabular}

aTested between lidocaine and articaine groups.

bNon significant, Fisher's Exact Test.

Table 6. Overall success rates of treatments after lidocaine and articaine infiltration for all 41 patients included in the present study

\begin{tabular}{cccccccc}
\hline \multirow{2}{*}{ Treatment outcome and solution used } & \multicolumn{2}{c}{ Lidocaine } & \multicolumn{2}{c}{ Articaine } & \multicolumn{2}{c}{ Total } & \multirow{2}{*}{ P value $^{\mathrm{a}}$} \\
\cline { 2 - 7 } & $\mathbf{N}$ & $\mathbf{\%}$ & $\mathbf{N}$ & $\mathbf{\%}$ & $\mathbf{N}$ & $\mathbf{\%}$ & \\
\hline Successful treatment without pain & 19 & 90.5 & 14 & 70 & 33 & 80.5 & $0.13^{\mathrm{b}}$ \\
Failure of treatment due to pain & 2 & 9.5 & 6 & 30 & 8 & 19.5 & \\
\hline
\end{tabular}

${ }^{a}$ Tested between lidocaine and articaine groups.

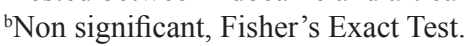

Table 7. Summary of results after lidocaine and articaine infiltrations for all 41 patients included in the present study

\begin{tabular}{lcccccccc}
\hline \multirow{2}{*}{ Outcomes measure and solution used } & \multicolumn{2}{c}{ Lidocaine } & \multicolumn{2}{c}{ Articaine } & \multicolumn{2}{c}{ Total } & \multirow{2}{*}{ P value $^{\mathrm{a}}$} \\
\cline { 2 - 7 } & $\mathbf{N}$ & $\mathbf{\%}$ & $\mathbf{N}$ & $\mathbf{\%}$ & $\mathbf{N}$ & $\mathbf{\%}$ & \\
\hline \multirow{2}{*}{ Total number of patients } & 21 & 51.2 & 20 & 48.8 & 41 & 100 & \\
\hline \multirow{2}{*}{ Sex } & Male & 6 & 14.6 & 9 & 22 & 15 & 36.6 & \multirow{2}{*}{$0.341^{\mathrm{b}}$} \\
\cline { 2 - 8 } & Female & 15 & 36.6 & 11 & 26.8 & 26 & 63.4 & \\
\hline Successful initial anaesthesia & 21 & 100 & 19 & 95 & 40 & 97.5 & $0.488^{\mathrm{b}}$ \\
\hline Successful treatment without pain & $19 / 21$ & 90.5 & $14 / 19$ & 73.7 & $33 / 40$ & 82.5 & $0.226^{\mathrm{b}}$ \\
\hline Overall rate of pain-free treatment & $19 / 21$ & 90.5 & $14 / 20$ & 70 & $33 / 41$ & 80.5 & $0.13^{\mathrm{b}}$ \\
\hline
\end{tabular}

${ }^{a}$ Tested between lidocaine and articaine groups.

bNon significant, Fisher's Exact Test.

difference in the incidence of pain-free treatment between lidocaine and articaine groups (Fisher's Exact Test, $\mathrm{P}=0.13$ ). Table 7 provides an overall summary of the present results for the lidocaine and articaine groups.

\section{DISCUSSION}

In $2000,4 \%$ articaine $(1: 100,000)$ was given FDA approval for use in the United States and has been steadily growing in popularity [12]. Following its FDA approval, $4 \%$ articaine has proven to be safe and effective for use as a dental local anesthetic for both maxillary and mandibular procedures $[\underline{1}, \underline{4}, \underline{7}, \underline{9}, \underline{13}, \underline{14}]$. For dental procedures, $2 \%$ lidocaine with epinephrine is considered the "gold standard", and the anesthetic to which others are often compared [12]. A wide variety of studies have been conducted to compare the safety and efficacy of $4 \%$ articaine to the standard local anesthetic, $2 \%$ lidocaine, with varying outcomes $[1-10]$. These two local anesthetic solutions were selected because they are two of the most commonly used preparations used in the practice of dentistry in the United States, and this study aimed to approximate standard clinical practice [11].

As discussed by Kanaa et al. [1] inconsistent results have been obtained in the comparison of $2 \%$ lidocaine to $4 \%$ articaine, with the latter proving to be more effective in obtaining pulpal anaesthesia after mandibular infiltration [1,3-5], while no difference in efficacy was noted after inferior alveolar nerve block [1, 15-18]. A similarly inconsistent set of results emerges when comparing lidocaine and articaine solutions administered via infiltration in the maxilla. The volunteer trial by Kanaa et al. [1] found no significant difference in ability to achieve pulpal anaesthesia when evaluating the efficacy of these two solutions when administered via buccal infiltration. This finding was mirrored by another study by Costa et al. [7], which found no statistical difference in anesthetic success of lidocaine and articaine in the anaesthesia of maxillary posterior teeth. Other studies have failed to demonstrate a difference in efficacy between these two solutions in the anaesthesia of maxillary central incisors and 
maxillary canines $[\underline{8}, \underline{10}, \underline{15}]$.

On the contrary, a study by Evans et al. [13] found $4 \%$ articaine to be superior to $2 \%$ lidocaine in the anaesthesia of maxillary lateral incisors. In the investigation of the anaesthesia of maxillary posterior teeth with irreversible pulpitis, Srinvasan et al. [6] found $4 \%$ articaine to be superior to $2 \%$ articaine at a highly significant level. In perhaps one of the most extensive reviews of the literature to date, Brandt et al. [] found in their meta analysis that $4 \%$ articaine proves to be 2.44 to 3.81 times more effective than $2 \%$ lidocaine when given as infiltration.

Because of these highly varied results in the anaesthesia of maxillary teeth, the results of the present study are congruent with some prior research, but contradictory to others. We found no statistically significant difference in the anesthetic efficacy of lidocaine and articaine in the anaesthesia of maxillary posterior teeth with irreversible pulpitis. Our results are consistent with those obtained by Kanaa et al. [1], which is most similar in methodology to the present study. In their study, no significant difference was found in the efficacy of lidocaine and articaine with respect to pain-free treatment of maxillary teeth with irreversible pulpitis. Kanaa et al. [1] found a $96.2 \%$ success rate of pain-free extraction, while our success rate was slightly lower at $80.5 \%$.

Our results differ from the study by Srinivasan et al. [6], in which the efficacy of these local anesthetic solutions in maxillary posterior teeth with irreversible pulpitis was investigated. In that study, it was found that $4 \%$ articaine offered a significant advantage in the anaesthesia of both premolars and molars, whereas the present study found no differences in efficacy between lidocaine or articaine solutions.

It should be noted, however, that while the efficacy of lidocaine and articaine in the present study did not differ at the statistically significant level $(P=0.13)$, the lidocaine group did show a $20.5 \%$ higher success rate in achieving treatment with no reported pain, which could be significant in a clinical setting considering the limited number of patients included in this study.

The results of the present study and other studies which demonstrated contradictory results exhibit differences in sample size, tooth type variances, anesthetic doses, concentration of vasoconstrictor, and the study definition of success. In the current study, $3.6 \mathrm{~mL}$ of $2 \%$ lidocaine with $1: 100,000$ epinephrine and $1.8 \mathrm{~mL}$ of $4 \%$ articaine with 1:100,000 epinephrine were compared. Kanaa et al. [1] employed $2.0 \mathrm{~mL}$ volumes of $2 \%$ lidocaine with 1:80,000 epinephrine and $4 \%$ articaine with 1:100,000 epinephrine. Srinivasan et al. [] ] employed a $1.7 \mathrm{~mL}$ volume of solutions in their study. The $3.6 \mathrm{~mL}$ lidocaine and $1.8 \mathrm{~mL}$ articaine volumes were used in the present study in an attempt to elucidate any difference in efficacy when equal doses (in milligrams) of each anesthetic were employed.

The definition of treatment success in the present study was similar to that employed by Kanaa et al. [1], in that success was defined as pain-free treatment. Other studies included mild pain in their definition of treatment success $[\underline{1}, \underline{6}, \underline{15}]$, which may help to explain the differences in reported outcomes. In the present study, successful treatment was completed on 33 of 40 $(82.5 \%)$ patients with successful initial anaesthesia, or 33 of the total $41(80.5 \%)$ patients initially included. This figure is higher than the study by Kanaa et al. [1], who achieved pain-free treatment in $84.9 \%$ of patients with successful pulpal anaesthesia and $62 \%$ of all patients recruited.

The likely difference in treatment success rates between the present study and those by Kanaa et al. [1], Srinivasan [6], and others, is that treatment success in the present study depended solely on a pain-free extraction. Other studies included extraction as well as other treatment modalities such as pulp extirpation in their outcomes measures $[\underline{1-10}]$. This is something that should be considered when comparing the present results against other investigations, since it has been shown that obtaining anaesthesia for extraction procedures on teeth with irreversible pulpitis is simpler and more successful than procedures such as pulp extirpation $[\underline{1}, \underline{18}, \underline{19}]$. When comparing the present results with the study by Kanaa et al. [1] , and limiting the comparison to extractions only, an $80.5 \%$ success rate is found in the present study, versus a $70 \%$ success rate in the previous study. This may be attributable to the increased quantity of vasoconstrictor administered in the lidocaine group ( $0.036 \mathrm{mg}$ epinephrine versus $0.022 \mathrm{mg}$ ) in the present study versus the previous study by Kanaa et al. [1], although present research may not support this assertion [20].

The present symptoms or reason for extraction of maxillary teeth may play an important role in evaluating the outcomes of research directed at evaluating efficacy of anesthetic solutions. Teeth with irreversible pulpitis are 8 times more likely to experience failure of anaesthesia than normal teeth, so the results of the present study may not be applicable to patients undergoing extraction or other treatment of maxillary teeth that are not experiencing irreversible pulpitis $[\underline{21}, 22]$. The present study was conducted as a caseseries, and as such, only a small patient pool was utilized with no patient or clinician blinding. This may lead to significant selection, operator, or patient biases. A future full clinical trial should include multiple treatment modalities and a blinded randomized protocol to mitigate these problems. Furthermore, future research 
would require a specific number of patients in order to achieve the desired confidence interval and level of statistical significance required for a full prospective clinical trial. Without making such attempts to eliminate bias and increase the size of the subject pool, no specific clinical recommendations can be made from the results of the present study. It is up to the reader to draw their own conclusions and to hopefully investigate the subject further through future research.

\section{CONCLUSIONS}

A combined buccal and palatal infiltration with $72 \mathrm{mg}$ $2 \%$ lidocaine with 1:100,000 epinephrine or $72 \mathrm{mg} 4 \%$ articaine with 1:100,000 epinephrine exhibited similar success rates of preliminary anaesthesia and similar pain-free treatment in patients undergoing simple extraction of a single tooth with irreversible pulpitis in the posterior maxilla. Success rates of treatment were the same for molars and premolars undergoing extractions, both within the same anesthetic group, and between the lidocaine and articaine groups.

\section{ACKNOWLEDGEMENTS AND DISCLOSURE STATEMENTS}

The authors do not report any conflicts of interest related to this study. The authors do not have any financial interests, either directly or indirectly, in the products or information listed in the paper.

\section{REFERENCES}

1. Kanaa MD, Whitworth JM, Meechan JG. A comparison of the efficacy of $4 \%$ articaine with 1:100,000 epinephrine and $2 \%$ lidocaine with 1:80,000 epinephrine in achieving pulpal anesthesia in maxillary teeth with irreversible pulpitis. J Endod. 2012 Mar;38(3):279-82. Epub 2011 Dec 22. [Medline: 22341059] [doi: 10.1016/j.joen.2011.11.010]

2. Haase A, Reader A, Nusstein J, Beck M, Drum M. Comparing anesthetic efficacy of articaine versus lidocaine as a supplemental buccal infiltration of the mandibular first molar after an inferior alveolar nerve block. J Am Dent Assoc. 2008 Sep;139(9):1228-35. Erratum in: J Am Dent Assoc. 2008 Oct;139(10):1312. [Medline: 18762633]

3. Jaber A, Whitworth JM, Corbett IP, Al-Baqshi B, Kanaa MD, Meechan JG. The efficacy of infiltration anaesthesia for adult mandibular incisors: a randomised double-blind cross-over trial comparing articaine and lidocaine buccal and buccal plus lingual infiltrations. Br Dent J. 2010 Nov;209(9):E16. Epub 2010 Oct 15. [Medline: 20953168] [doi: 10.1038/sj.bdj.2010.974]

4. Robertson D, Nusstein J, Reader A, Beck M, McCartney M. The anesthetic efficacy of articaine in buccal infiltration of mandibular posterior teeth. J Am Dent Assoc. 2007 Aug;138(8):1104-12. [Medline: 17670879]

5. Kanaa MD, Whitworth JM, Corbett IP, Meechan JG. Articaine and lidocaine mandibular buccal infiltration anesthesia: a prospective randomized double-blind cross-over study. J Endod. 2006 Apr;32(4):296-8. Epub 2006 Feb 17. [Medline: 16554198] [doi: 10.1016/j.joen.2005.09.016]

6. Srinivasan N, Kavitha M, Loganathan CS, Padmini G. Comparison of anesthetic efficacy of $4 \%$ articaine and $2 \%$ lidocaine for maxillary buccal infiltration in patients with irreversible pulpitis. Oral Surg Oral Med Oral Pathol Oral Radiol Endod. 2009 Jan;107(1):133-6. [Medline: 19101495] [doi: 10.1016/j.tripleo.2008.09.002]

7. Costa CG, Tortamano IP, Rocha RG, Francischone CE, Tortamano N. Onset and duration periods of articaine and lidocaine on maxillary infiltration. Quintessence Int. 2005 Mar;36(3):197-201. [Medline: 15887505]

8. Brandt RG, Anderson PF, McDonald NJ, Sohn W, Peters MC. The pulpal anesthetic efficacy of articaine versus lidocaine in dentistry: a meta-analysis. J Am Dent Assoc. 2011 May;142(5):493-504. [Medline: 21531931]

9. Winther JE, Nathalang B. Effectivity of a new local analgesic Hoe 40 045. Scand J Dent Res. 1972;80(4):272-8. [Medline: 4560609]

10. Ruprecht S, Knoll-Köhler E. [A comparative study of equimolar solutions of lidocaine and articaine for anesthesia. A randomized double-blind cross-over study]. Schweiz Monatsschr Zahnmed. 1991;101(10):1286-90. German. [Medline: 1947972]

11. Moore PA, Nahouraii HS, Zovko JG, Wisniewski SR. Dental therapeutic practice patterns in the U.S. I. Anesthesia and sedation. Gen Dent. 2006 Mar-Apr;54(2):92-8. [Medline: 16689062]

12. Malamed SF, Gagnon S, Leblanc D. Articaine hydrochloride: a study of the safety of a new amide local anesthetic. J Am Dent Assoc. 2001 Feb;132(2):177-85. [Medline: 11217590]

13. Evans G, Nusstein J, Drum M, Reader A, Beck M. A prospective, randomized, double-blind comparison of articaine and lidocaine for maxillary infiltrations. J Endod. 2008 Apr;34(4):389-93. Epub 2008 Feb 7. [Medline: 18358883] [doi: 10.1016/j.joen.2008.01.004]

14. Uckan S, Dayangac E, Araz K. Is permanent maxillary tooth removal without palatal injection possible? Oral Surg Oral Med Oral Pathol Oral Radiol Endod. 2006 Dec;102(6):733-5. Epub 2006 Mar 20. Erratum in: Oral Surg Oral Med Oral Pathol Oral Radiol Endod. 2007 Apr;103(4):580. [Medline: 17138173] [doi: 10.1016/j.tripleo.2005.12.005] 
15. Claffey E, Reader A, Nusstein J, Beck M, Weaver J. Anesthetic efficacy of articaine for inferior alveolar nerve blocks in patients with irreversible pulpitis. J Endod. 2004 Aug;30(8):568-71. [Medline: 15273637] [doi: 10.1097/01.DON.0000125317.21892.8F]

16. Mikesell P, Nusstein J, Reader A, Beck M, Weaver J. A comparison of articaine and lidocaine for inferior alveolar nerve blocks. J Endod. 2005 Apr;31(4):265-70. [Medline: 15793381] [doi: 10.1097/01.don.0000140576.36513.cb]

17. ierra Rebolledo A, Delgado Molina E, Berini Aytís L, Gay Escoda C. Comparative study of the anesthetic efficacy of 4\% articaine versus $2 \%$ lidocaine in inferior alveolar nerve block during surgical extraction of impacted lower third molars. Med Oral Patol Oral Cir Bucal. 2007 Mar 1;12(2):E139-44. [Medline: 17322803]

18. Tortamano IP, Siviero M, Costa CG, Buscariolo IA, Armonia PL. A comparison of the anesthetic efficacy of articaine and lidocaine in patients with irreversible pulpitis. J Endod. 2009 Feb;35(2):165-8. Epub 2008 Dec 12. [Medline: 19166765] [doi: 10.1016/j.joen.2008.10.020]

19. Miller AG. A clinical evaluation of the Ligmaject periodontal ligament injection syringe. Dent Update. 1983 NovDec;10(10):639-40, 642-3. [Medline: $\underline{6594289}$ ]

20. McEntire M, Nusstein J, Drum M, Reader A, Beck M. Anesthetic efficacy of 4\% Articaine with 1:100,000 epinephrine versus 4\% articaine with 1:200,000 epinephrine as a primary buccal infiltration in the mandibular first molar. J Endod. 2011 Apr;37(4):450-4. [Medline: 21419288] [doi: 10.1016/j.joen.2010.12.007]

21. Aggarwal V, Singla M, Miglani S, Ansari I, Kohli S. A prospective, randomized, single-blind comparative evaluation of anesthetic efficacy of posterior superior alveolar nerve blocks, buccal infiltrations, and buccal plus palatal infiltrations in patients with irreversible pulpitis. J Endod. 2011 Nov;37(11):1491-4. [Medline: 22000449] [doi: 10.1016/j.joen.2011.08.018]

22. Hargreaves KM, Keiser K. Local anesthetic failure in endodontics: me chanisms and management. Endod Topics. 2002 Nov;1(1):26-39. [doi: 10.1034/j.1601-1546.2002.10103.x]

\section{To cite this article:}

Friedl CC, Bashutski J, Rashidi N. A Comparison of Equivalent Doses of Lidocaine and Articaine in Maxillary Posterior Tooth Extractions: Case Series.

J Oral Maxillofac Res 2012;3(2):e4

URL: http://www.ejomr.org/JOMR/archives/2012/2/e4/v3n2e4ht.pdf

doi: $10.5037 /$ jomr.2012.3204

Copyright (C) Friedl CC, Bashutski J, Rashidi N. Accepted for publication in the JOURNAL OF ORAL \& MAXILLOFACIAL RESEARCH (http://www.ejomr.org), 28 June 2012

This is an open-access article, first published in the JOURNAL OF ORAL \& MAXILLOFACIAL RESEARCH, distributed under the terms of the Creative Commons Attribution-Noncommercial-No Derivative Works 3.0 Unported License, which permits unrestricted non-commercial use, distribution, and reproduction in any medium, provided the original work and is properly cited. The copyright, license information and link to the original publication on (http://www.ejomr.org) must be included. 